\section{Attitudes towards music as a means of therapy: can it help to overcome depression and/or cardiovascular disease?}

\section{Vaitsa Giannouli \\ School of Medicine, Aristotle University of Thessaloniki, Greece}

Music is well-known for its healing properties since the time of the ancient Greek asclepieia. Exposure to various genres of music (e.g. classical) is widely claimed to improve quality of life and serve as an effective way for the reduction of pain, reduction of blood pressure, improvement in cardiorespiratory variables, such as heart rate (HR) and heart rate variability (HRV), reduction of chronic headaches and migraines, boosting of immunity and at the same time it is claimed to enhance intelligence, learning and IQ (especially memory performance, concentration, attention, reading and literacy skills, spatialtemporal reasoning and mathematical abilities).1-5 Although, not all studies show the same magical influence of music on human health and cognition, ${ }^{6-11}$ it is interesting to explore what are the attitudes of people for music, health and psychology, especially from a different cultural and musical background (as is the case for Greece).

The purpose of this study was to reveal something still unknown: the attitudes that young adults have for music and its applications on psychology-psychiatry. 300 volunteers (188 women, 112 men; mean age $=21.91$ years, $\mathrm{SD}=$ 4.95) filled a short demographic survey (age, sex, education, profession) along with a brief semi-structured questionnaire. The participants were all non-musicians and non-patients at the time of the examination. They were asked to write down their views about music and its applications on nuclear medicine and music and psychology/psychiatry. ${ }^{12}$

The main questions at which they had to respond were: 1 . Can music help you with a physical problem? (67\% yes, $33 \%$ no), 2 . What kind of problem (heart diseases 56\%, hypertension 44\%), 3. Can music improve the quality of life in chronic disease? ( $82 \%$ yes, $18 \%$ no), 4 . In what way does music influence your health? (through regulation of the impact that the emotion has on my health $54 \%$, through regulation of the impact that the cognition has on my health $30 \%$, in a still unknown way $16 \%$ ) 5. Can music help you pass a psychological problem? (78\% yes, $22 \%$ no), 6 . What kind of problem (major depression 54\%, anxiety disorders $46 \%)$, 7. Can music improve your cognitive performance? (69\% yes, $31 \%$ no), 8 . What kind of cognitive tasks do you believe that can be improved with music? (spatial-temporal reasoning tasks $42 \%$, mathematical tasks $30 \%$, attention 28\%), 9. In which way can it help you? (passive listening 56\%, playing an instrument $20 \%$, singing in a choir $24 \%$ ), 10 . Which would you prefer, if only one was available for you? (passive listening of favorite pieces $86 \%$ ), 11 . Why? (it is available at any time $34 \%$, at low cost $40 \%$, it does not stigmatize me as a patient $26 \%), 12$. What would you propose to psychiatrists and mental health experts? [Introduce music therapy, passive (also called music medicine) and active-creative music therapy to the public $67 \%$, combine classic techniques and new ones involving music $20 \%$, try at first music therapy interventions (especially for depression) and continue in parallel with classic psychotherapy or pills 13\%]. For all the above questions statistical analyses did not show any differences between men-women and educational and professional groups.

Exploring people's ideas and expectations about the connection of music and health-illness (especially mental health), backs up what might always have seemed like common sense, that music may help us alter our physical and mental status. So, music could be used in accompanying psychological interventions concerning health and disease and/or rehabilitation programs. Even if music's influence on health is not yet fully scientifically proved, the vast majority of young Greeks see it as a tool for change, and these perceived benefits of music should be further explored and incorporated in health services, such as the general hospital.

\section{References}

1. Brocklesby R. Reflections on the power of music. London: M. Cooper; 1749.

2. Sakalak I. Musical vitamins. Elements of music medicine and music psychology. Athens: Fagotto publications; 2004.
Correspondence: Vaitsa Giannouli, School of Medicine, Aristotle University of Thessaloniki, Arkadiou 11, Drama 66100, Greece.

E-mail giannouliv@hotmail.com

Received for publication: 4 February 2013. Accepted for publication: 4 February 2013.

This work is licensed under a Creative Commons Attribution NonCommercial 3.0 License (CC BYNC 3.0).

(C) Copyright V. Giannouli, 2013

Licensee PAGEPress, Italy

Health Psychology Research 2013; 1:e7

doi:10.4082/hpr.2013.e7

3. Dritsas, T. Music medicine. texts and comments on the therapeutic potential of music. Athens: Info Health; 2003.

4. Trappe HJ. Role of music in intensive care medicine. Int J Crit Illn Inj Sci 2012;2:2731.

5. Bernardi L, Porta C, Casucci G, et al. Dynamic interactions between musical, cardiovascular, and cerebral rhythms in humans. Circulation 2009;119:3171-80.

6. Steele KM, Ball TN, Runk R. Listening to Mozart does not enhance backwards digit span performance. Percept Mot Skills 1997;84:1179-84.

7. Steele KM, Brown JD, Stoecker JA. Failure to confirm the Rauscher and Shaw description of recovery of the Mozart effect. Percept Mot Skills 1999;88:843-8.

8. Steele KM, Bass KE, Crook MD. The mystery of the Mozart effect: failure to replicate. Psychologic Sci 1999;10:366-9.

9. Bridgett DJ, Cuevas J. Effects of listening to Mozart and Bach on the performance of a mathematical test. Percept Mot Skills 2000;90:1171-5.

10. Lints A, Gadbois S. Is listening to Mozart the only way to enhance spatial reasoning? Percept Mot Skills 2003;97:1163-74.

11. Fudin R, Lembessis E. The Mozart effect: questions about the seminal findings of Rauscher, Shaw and colleagues. Percept Mot Skills 2004;98:389-405.

12. Giannouli V, Lytras N, Syrmos N. Is there a place for music in nuclear medicine? Hell J Nucl Med 2012;188-9. 